\title{
GENERATION OF NANOPARTICLES IN THE CONCENTRATED ENERGY (LASER BEAM) AND GAS FLOW
}

\author{
A. Amulevičius, Č. Sipavičius, A. Daugvila, R. Davidonis
}

Nuclear and environmental radioactivity research laboratory, Institute of Physics, Savanoriu av. 231, LT-02300

Vilnius, Lithuania.E-mail: sipp@ar.fi.lt, antanas@ar.fi.lt

Received 3005 2004, accepted 07102004

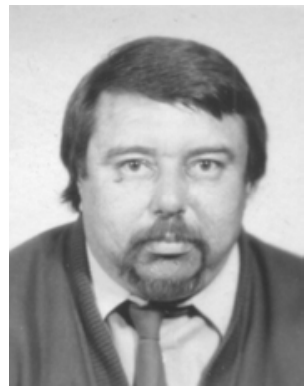

Arūnas Severas AMULEVIČIUS, Ph. D. works at the Institute of Physics as a senior researcher. He is head of the group of the Nuclear Research Laboratory. E-mail antanas@ar.fi.lt

In 1968 he graduated from Vilnius State University with a degree in Physics and Radiophysics.

In 1968-1973 he was a PhD student at Moscow Institute of Chemical Physics. In 1973 he defended his doctoral thesis.

He is author of 80 scientific papers.

His research areas are chemical physics and magnetic properties of nanoparticles.

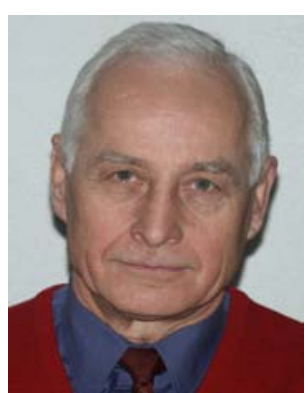

Česlovas Steponas SIPAVIČIUS is a Doctor of technical sciences and is a senior research associate at the Institute of Physics. E-mail sipp@ar.fi.lt.

He graduated from Kaunas Polytechnic Institute in 1962. In 1962-1968 he worked in the Vilnius Plastics goods plant as engineer-technologist. In 1968-1983 he worked as a scientific secretary at the technical-mathematical sciences department of the Lithuanian Academy of Sciences. In 1976 he completed post-graduate studies at the Institute of Physical-technical Energy Problems and in 1978 received a PhD degree. In 1983-1986 he worked as a senior lecturer at the Vilnius Pedagogical Institute. Since 1986 he has been working at the Institute of Physics in the Laser Technology Laboratory, Materials Science Laboratory (head of laboratory) and Nuclear and Environmental Radioactivity Research Laboratory.

$\mathrm{He}$ is author and co-author of more than 150 publications on the problems of thermal exchange, laser technology, and laser beam interaction with material. He has participated in more than 30 domestic and international scientific conferences. His major works have been published in the journals "Power Engineering" (Journal the Lithuanian Academy of Sciences), "Materials Science" (Kaunas), "Transactions of Academy of Sciences of Russia (Physical series)", "The Physics of Metals and Metallography" (Russia), "Physics of Metals and Modern Technology" (Ukraine).

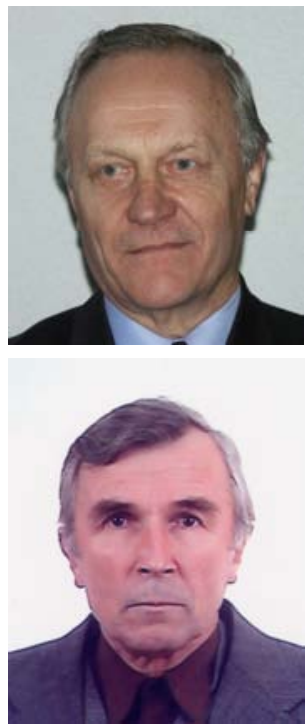

Antanas DAUGVILA works at the Laboratory of Nuclear and Environmental Radioactivity Research of the Institute of Physics as a senior engineer. E-mail antanas@ar.fi.lt

In 1963 he graduated from Vilnius State University with a degree in Mathematics.

From 1964 to 1978 he worked at the Institute of Physics-Mathematics. He has been working at the Institute of Physics since 1978.

He is author of 80 scientific papers.

His research areas are environmental physics, magnetic properties of nanoparticles, and materials science.

Rimantas DAVIDONIS, works at the Laboratory of Nuclear and Environmental Radioactivity Research of the Institute of Physics as a senior engineer. E-mail antanas@ar.fi.lt

In 1959 he graduated from Vilnius State University with a degree in Physics (optics, spectroscopy).

He has been working at the Institute of Physics since 1963.

$\mathrm{He}$ is author of 100 scientific papers.

His research areas are environmental physics, magnetic properties of nanoparticles, and materials science.

Abstract. The method of generation and selection of small nanoparticles in the airflow is considered in this paper. To melt the material (stainless steel), a concentrated energy flow - a pulsed solid-state laser beam - was used. Using the Mőssbauer spectroscopy method, the particle sizes and their chemical composition at various distances from the melting place were determined. The influence of parameters of the laser beam power and the airflow on the size of particles and their chemical composition was investigated.

Keywords: nanoparticles, generation and selection of particles, laser beam, laser technology, laser cutting, nozzle, gas (air) flow, stainless steel, erosion products. 


\section{Introduction}

Production of micro dispersive material or nanoparticles is a technically complicated and economically expensive process. The aim of this work is to consider and propose a method of production and selection of small particles of stainless steel using laser beam power. The idea is based on the fact that particles of a desirable size and chemical composition can be generated from the laser cutting erosion products in the airflow. The laser beam is used as the concentrated energy source that destroys the material, and the airflow activates the erosion process and particle oxidation. The question of whether such material is marketable arises. The answer is yes. The synthesized particles possess properties of magnetites or supermagnetites. Therefore, by admixing the hydraulic liquids with particles, it is possible to change the viscosity of these liquids by a remote method. Magnetic liquids are successfully used in the production of dampers of powerful vehicles and elsewhere.

\section{The investigation methods}

Two types of stainless steel, 30X13 (Russian) and 7C27Mo2 (Sandvik, Sweden) of similar carbon, chromium, and molybdenum composition were used in the investigations. The thickness of the strip used varied from $0.3 \mathrm{~mm}$ to $0.9 \mathrm{~mm}$. During the experiment, the velocity of the material and laser beam movement can be changed from $100 \mathrm{~mm}$ to $2000 \mathrm{~mm}$ per minute.

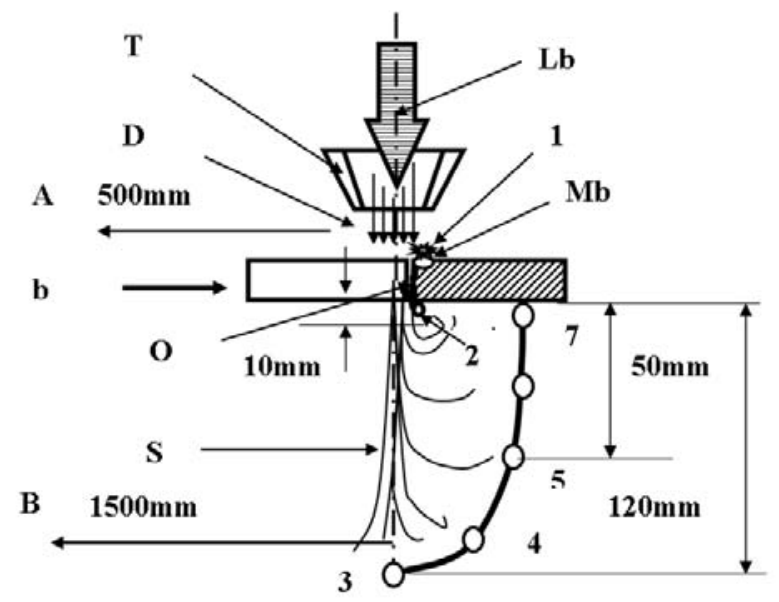

Fig 1. Nanoparticle generation and selection in the concentrated power and gas flow. $\mathbf{1}-\mathbf{7}$ are sites particle collection from chamber-catcher, or 500 and $1500 \mathrm{~mm}$ from the laser beam action zone, $\mathbf{A}$ - B the direction of particle movement, $\mathbf{D}$ - gas flow, Lb - laser beam, Mb- melt bath, O- oxide film, $\mathbf{S}$ - erosion product flow, $\mathbf{T}$ - nozzle, $\mathbf{b}$ - the sample

A solid-state pulsed Nd: YAG laser with an average power of $250 \mathrm{~W}$ was used. The wavelength of the pulse generated was $1064 \mathrm{~nm}$, the duration was $2 \pm 0.6 \mathrm{~ms}$, and the repetition frequency was $150 \pm 3 \mathrm{~Hz}$ [5].

The samples were collected in a special chambercatcher (Figure 1), where the air and erosion product flow was directed. In this device, the particle samples were collected at distances of $1 \mathrm{~mm}, 10 \mathrm{~mm}, 50 \mathrm{~mm}$, and 120 $\mathrm{mm}$ from the place the material was destroyed. Apart from the indicated places, the samples were collected at a distance of $500 \mathrm{~mm}$ from the upper edge of the work piece (free particle flight) and at a distance of $1500 \mathrm{~mm}$ from the place of destruction where the carried particle fully cools down $[2,4]$.

The material of prepared samples was deposited on the $20-\mu \mathrm{m}$-thick aluminum foil and placed into the Mössbauer spectrometer. Mössbauer spectra were measured with the standard spectrometer with a ${ }^{57} \mathrm{Co}$ rhodium source. The measurements were carried out at room temperature. The program of the least-squares method, which enables varying and controlling up to 100 spectrum parameters, was used in the spectra processing.

\section{Discussion of experimental results}

It is known that material destruction under the action of the laser beam occurs at $2000-3000 \mathrm{~K}$. At this temperature during the cutting, the melt is in liquid state for some milliseconds $(\mathrm{t}=\mathrm{d} / \mathrm{v})$, because depending on the technological gas composition used the material melting and cooling down takes place at the velocity of about $10^{5}$ $-10^{6} \mathrm{~K} / \mathrm{s}$. The energy flow, gas chemical composition, and flow velocity will determine the size and chemical composition of the eroded product particles in the material melting zone and outside this zone. The dispersion of the eroded product and phase composition make it possible to decide about particle formation at initial and further stages of material destruction. Most of the parameters are relevant in these investigations. The dynamics of the particle mixing in the airflow, the atom diffusion and the variation of the particle phase composition from its formation till full cooling down have been determined. These data enable one to determine the peculiarities of the melted formation under non-stationary conditions.

Quite a number of data on the close chemical order in the alloy crystal lattice after the synthesis of these materials under the action of the laser beam have been obtained in earlier investigations [4]. They show that materials obtained in this way can be attributed to the class of multiphase nanocrystal materials.

The results of the Mössbauer spectral analysis of the samples are shown in Figure 2 and Table 1. Relative amounts of various iron atoms surrounded by chromium atoms in the first and second coordination lattice spheres are also presented in Table 1. Data were compared with the stochastic model of $\mathrm{Cr}$ or Mo distribution in the alloy, and occupation (population) for the theoretical first and second coordination spheres were determined. In order to approximate the theoretical and experimental results, parameters of short-range and long-range order are introduced.

The data presented in Table 1 show some regularity between the laser beam power, movement (cutting) velocity, and particle-flown path to their sampling place. The Mössbauer spectral analysis of the material shows that under complicated conditions of the impact on the material the following components of the $\mathrm{Fe}-\mathrm{Cr}$ system are formed: solid $\mathrm{Fe}-\mathrm{Cr}$ solutions, paramagnetic $\gamma-\mathrm{Fe}(\mathrm{Cr})$ phases, various $\mathrm{Fe}$ and $\mathrm{Cr}$ oxides, clusters, etc. 

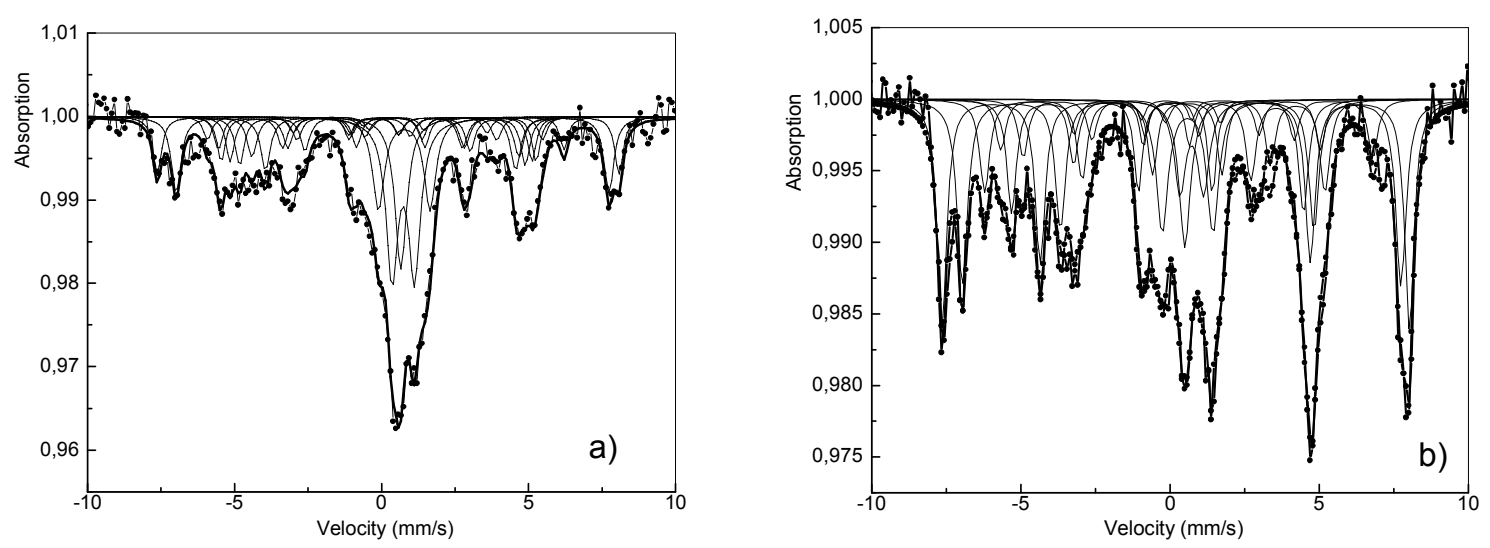

Fig 2. Mössbauer spectra of the samples. a) - erosion products collected from lower edge of the part, b) - erosion products collected at a distance of $500 \mathrm{~mm}$ from the cut zone

Table 1. Phase composition of the samples

\begin{tabular}{|c|c|c|c|c|c|}
\hline Exsperiment & $\begin{array}{l}\text { Superparamagnetic and } \\
\text { paramagnetic phase } \%\end{array}$ & $\begin{array}{l}\text { Magnetic } \mathrm{FeCr} \\
\text { phase, } \% \text { - } \mathrm{Cr} \%\end{array}$ & $\begin{array}{c}\text { Magnetic } \\
\mathrm{Fe}_{3} \mathrm{O}_{4} \text { phase \% }\end{array}$ & $\begin{array}{c}\text { Magnetic } \\
(\mathrm{FeCr})_{3} \mathrm{O}_{4} \\
\text { phase } \%\end{array}$ & Location \\
\hline $\mathrm{I}-1$ & $\gamma \mathrm{Fe}(\mathrm{Cr}) \quad 16.56$ & $57.51-7.9$ & 15.99 & 9.95 & $\mathrm{a}$ \\
\hline I - 2 & $\gamma \mathrm{Fe}(\mathrm{Cr}) \quad 20.31$ & $66.03-9.0$ & -- & 3.69 & $\mathrm{c}$ \\
\hline I - 3 & $\gamma \mathrm{Fe}(\mathrm{Cr}) \quad 31 ., 88$ & $66.58-7.6$ & -- & 2.1 & $\mathrm{c}$ \\
\hline $\mathrm{I}-4$ & $\gamma \mathrm{Fe}(\mathrm{Cr}) \quad 45.44$ & $52.44-3.7$ & 3.0 & 2.11 & $\mathrm{~d}$ \\
\hline $\mathrm{I}-5$ & $\gamma \mathrm{Fe}(\mathrm{Cr}) \quad 69.04$ & $28.1-6.45$ & $<3.5$ & 2.87 & bottom \\
\hline II - 1 & $\gamma \mathrm{Fe}(\mathrm{Cr}) \quad 19.04$ & $17.5-5.4$ & 46.8 & 16.85 & $\mathrm{e}$ \\
\hline II - 2 & $\gamma \mathrm{Fe}(\mathrm{Cr}) \quad 26.13$ & 17.37 & 35.57 & 20.92 & $\mathrm{~g}$ \\
\hline II - 3 & $\gamma \mathrm{Fe}(\mathrm{Cr}) \quad 38.10$ & $25.85-7.8$ & 25.57 & 10.47 & $\mathrm{~b}$ \\
\hline
\end{tabular}

Notice: a- $10 \mathrm{~mm}$, b- workpiece edge, c- $1 \mathrm{~mm}, \mathbf{d}-50 \mathrm{~mm}$, bottom (chamber- catcher) - $120 \mathrm{~mm}, \mathbf{e}-500 \mathrm{~mm}, \mathbf{g}-1500 \mathrm{~mm}$

The Mőssbauer spectral analysis enables one to observe certain regularities and to classify the collected samples into some groups. The data of some groups in Table 1 are compared to the data presented in our earlier works [2].

We attributed particles deposited on the upper cut edge and collected from the chamber-catcher wall at a distance of $1 \mathrm{~mm}$ from the laser beam impact zone to the first group. The Fe-Cr magnetic phase (92-95\%), $\gamma$-Fe (Cr) super magnetic phase $(\sim 3.4 \%$ ), and small (to $4 \%$ ) $\mathrm{Fe}_{3} \mathrm{O}_{4}$ magnetic phases prevail in the composition of the first group particles. However, in the particle, another phase ratio, which can be influenced by the chosen laser beam power and the gas flow pressure in front of the nozzle, is also possible. If we increase the gas pressure in front of the nozzle up to 5-6 bars, at the place of the action there will be excess of gas (air), intensive mixing of the melt in the cut zone will take place, and the particle surface will oxidize intensively even at the initial cutting phase stage. The surface of these particles consists of the $\mathrm{Fe}_{3} \mathrm{O}_{4}$ magnetic phase and other $\mathrm{Fe}$ or $\mathrm{Cr}$ oxides. In this case, we will have the most favorable laser-cutting regime, which will be testified by easily mechanically cleaned particles of erosion products deposited on the cut edge. In case of the ideal choice of cutting parameters, erosion products are not formed on the lower edge of the work piece (Figure 3 ).

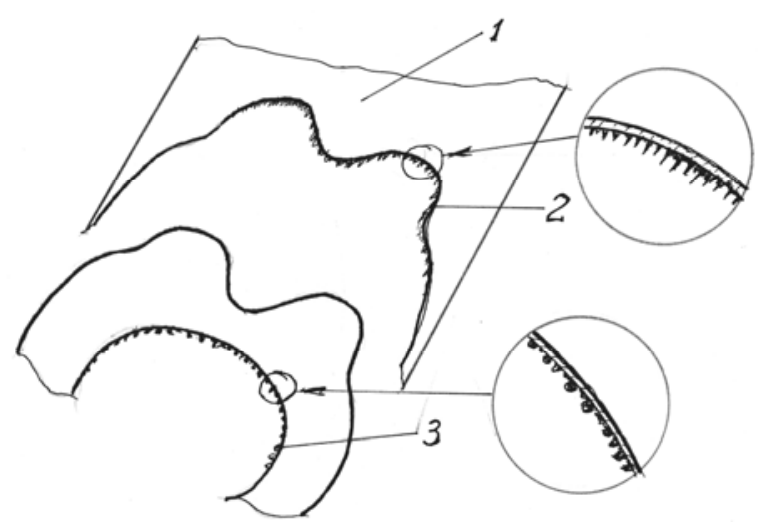

Fig 3. Scheme of erosion products deposited on the lower edge of the cut. 1- stainless steel band, 2- "icicle" form erosion products with prevailing super paramagnetic and magnetic $\mathrm{FeCr}$ phase in their composition, 3- "bubble" form erosion products with prevailing magnetic $\mathrm{Fe}_{3} \mathrm{O}_{4}$ and $(\mathrm{FeCr})_{3} \mathrm{O}_{4}$ phase

Samples collected from the chamber-catcher bottom at a distance of $120 \mathrm{~mm}$ from the cut zone are attributed to the second group. These particles are formed in the intensive mixing zone of the melt, and by flying in the airflow they continue to oxidize. Therefore, particles, as a rule, consist mainly of the $\mathrm{Fe}_{3} \mathrm{O}_{4}$ magnetic phase. 
Depending on the laser beam power, small amounts of $\alpha$ $\mathrm{Fe}_{3} \mathrm{O}_{4}$ and $\gamma-\mathrm{Fe}_{3} \mathrm{O}_{4}$ phases are found in the samples.

Samples collected from the device wall at a distance of $50 \mathrm{~mm}$ from the impact zone are attributed to the third group. The collected samples consist of fine and coarse magnetite $\left(\mathrm{Fe}_{3} \mathrm{O}_{4}\right)$ particles with an admixture of $\mathrm{Fe}-\mathrm{Cr}$ solid solution. The samples can be compared to the data analyzed in II -3 of Table 1,where the differently sized $\mathrm{Fe}_{3} \mathrm{O}_{4}$ magnetic phase makes up about $64 \%$ of the investigated material; the $\gamma-\mathrm{Fe}_{3} \mathrm{O}_{4}$ phase amounts to about $25 \%$, and magnetic $\mathrm{Fe}-\mathrm{Cr}$ phase admixtures constitute a small part [2].

We have attributed particles collected at a distance of $10 \mathrm{~mm}$ from the cut zone in the flow axis direction to the fourth group. The particles were formed in the active mixing zone of the flow. Their phase composition can therefore vary with the change in the laser beam power and the gas flow velocity. In the samples, the magnetic Fe-Cr phase $(\sim 65 \%)$ prevails, while the remaining part consists of the $\gamma$-Fe $(\mathrm{Cr})$ super magnetic phase, $\alpha-\mathrm{Fe}_{2} \mathrm{O}_{3}$ paramagnetic phase, and a small percentage of magnetic $\mathrm{Fe}_{3} \mathrm{O}_{4}$ phase.

Due to the fact that the laser beam and the nozzle are not often in alignment with each other, the nozzle slot defects the gas flow between the nozzle and the surface of the processed sample is distorted, therefore part of the destructed material is carried by the flow over the 500 $\mathrm{mm}$ distance and further from the cutting zone [3]. By fractionating the destructed material, this property can be used in the production of fine magnetic and paramagnetic particles. The collected particles are attributed to the fifth group. While flying over the distance of $\sim 500 \mathrm{~mm}$, the particles oxidize and cool down, and they are not larger than $20 \mathrm{~nm}$. They comprise from $70 \%$ to $\sim 98 \%$ of magnetic $\mathrm{Fe}_{3} \mathrm{O}_{4}$ phase and paramagnetic $\mathrm{Fe}_{3} \mathrm{O}_{4}$ phase. With an insufficient amount of air, up to $25 \%$ of $(\mathrm{FeCr})_{3} \mathrm{O}_{4}$ magnetite is sometimes formed.

The pumping system was installed in the device where the material particle fractionation took place. We placed a filter on which fully cooled down (and oxidized) particles were collected at a distance of $1500 \mathrm{~mm}$. The Mössbauer spectra have shown that these particles consist of very fine $\mathrm{Fe}_{3} \mathrm{O}_{4}$ magnetic phase.

During investigations we aimed to choose the optimal material destruction conditions during laser cutting. During each case of cutting, the laser beam power, the technological gas flow characteristics, and the geometry of nozzles that form the gas flow, were compared $[1,6]$. A real laser cutting process, when the laser beam power, the nozzle geometry, and the position are optimally chosen with respect to the processed work piece surface, is presented in Figure 4. It can be seen in the photo that the flow of the out flowing gas with erosion products is of the downward spread fan form with insignificant side vortices.

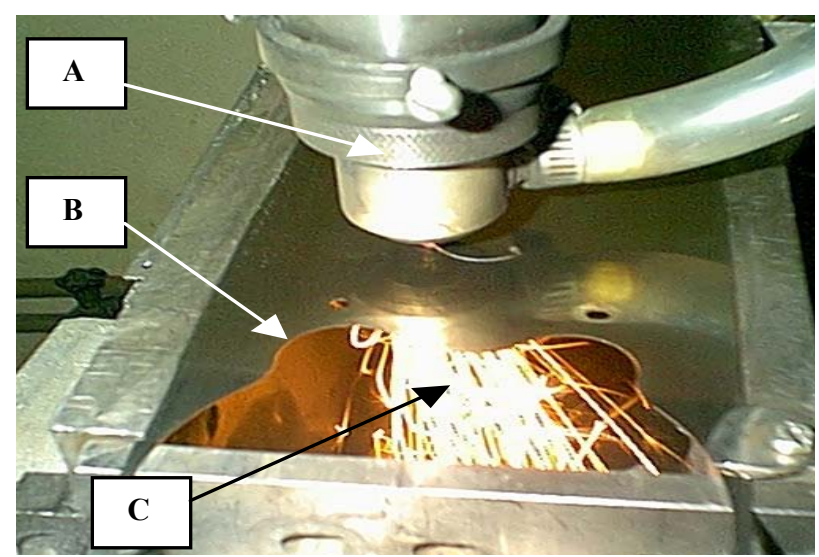

Fig 4. Particle generation and laser cutting device: A- nozzle (lens orifice), B- the work piece contour, $\mathbf{C}$ - gas (air) and particle flow out flowing from the cut slot

\section{Conclusions}

Generalizing the investigations performed we can state:

1. When a particle forms in the central (axial) part of the laser cut slot, where intensive mixing of gas and the melt takes place, the particle size and chemical composition will depend on the distance it flies from the laser action zone.

2. When the air pressure in front of the nozzle is higher than 3.5 bars, particles will be smaller and Fe and $\mathrm{Cr}$ oxides will prevail. When the air pressure in front of the nozzle is less than 2.0 bars, magnetic Fe-Cr system phases will prevail. The particles from the lower edges of the cut will be hard to clean mechanically. The cut is not qualitative.

\section{References}

1. Abilsitov G.A., Golubev V.S. Technological Lasers. Handbook - Moscow: Mashinostroenie, 1991. - P. 335-365 (in Russian).

2. Amulyavichyus A., Daugvila A., Davidonis R.et al. Chemical Composition of Nanostructured Erosion Products Produced upon Laser Cutting of Steel // The Physics of Metals and Metallography. - 1998. - Vol 85, No 1. - P. 84-89.

3. Patel R., Brewster M. Heat transfer in gas assisted metal drilling. Experimental results // Journal of Thermophysics and Heat Transfer. - 1991. - No 5(1). - P. 26-31.

4. Sipavičius Č., Amulevičius A. Application of a pulsed solid-state laser to precise countour cutting // Materials Science. - 1998. - No 2. - P. 56-59.

5. Sipavičius Č., Liolys L. Universal automated laser technogical komplex on the basis pulsed Nd: YAG laser // Materials Science. - Kaunas: Technologija, 1998. - Vol 26. - P. 91-95 (in Lithuanian).

6. Соколов Б.К., Терегулов В.М., Счастливцев В. и др. Актуальные вопросы лазерной обработки сталей и сплавов -Уфа: Изд. Технология, 1994. C. $30-57$. 